\title{
Investigation of Thermal Behavior of Lithium-Ion Batteries under Different Loads
}

\author{
Ceyda Kök ${ }^{1^{*}}$ (D), Alkan Alkaya² \\ 'Mersin University, Institute of Science and Technology, Department of Electrical Engineering, Mersin, Turkey \\ ${ }^{2}$ Mersin University, Faculty of Engineering, Electrical and Electronics Engineering Department, Mersin, Turkey
}

\begin{abstract}
In this study, the thermal behavior and performance of pouch type Lithium-Ion Batteries (LIB) which are used in Hybrid Electric Vehicles (HEVs) and Electrical Vehicles (EVs) has been investigated at different discharge rates based on numerical simulations. Numerical simulation was performed through a traditional software package using the dual potential Multi-Scale Multi-Dimensional (MSMD) battery model to analyze the cell discharge behavior and investigate its thermal performance. When the battery load is increased, non-uniform thermal distribution and temperature rise has been observed. Non-uniform thermal distribution causes loss of capacity and performance in the battery. Therefore, an accurate and effective cooling system is required to eliminate nonuniform temperature distribution. This study is a preliminary preparation for cooling system design.
\end{abstract}

Keywords: Electric vehicles, Pouch type lithium-ion battery, Battery modelling, Battery thermal management system, Heat distribution

\section{INTRODUCTION}

Motor vehicles which are increasing in proportion to the world population and become an indispensable part of our lives for transportation cause environmental pollution by using fossil fuels. Gases of gasoline and diesel fuel vehicles released into the atmosphere; $65 \%$ have carbon monoxide, $55 \%$ has nitrogen oxide and $45 \%$ has hydrocarbon [1]. The fact that thousands of vehicles emit these toxic gases every day not only confront us with the fact of environmental pollution, but also threatens our health. On the other hand, with the limited amount of fossil fuel sources and mainly due to greenhouse gases, the problems are accepted by everyone. With more attention to renewable energy, scientists have developed environmentally friendly tools such as EV, HEV, to alleviate this problem and to control the amount of toxic gas emitted [2]. The lead-acid and nickel-cadmium batteries used in these vehicles have not been effective until today due to the long charging time, low range problem, high battery prices and lack of charging stations. But; LIB which perform better than others today are used [3]. With the development of technology, portable electronic devices that enter our lives and make our lives easier, need a source of energy to work in a long and effective way. This energy source; reliable, long-lasting, easy to maintain, can be charged in a short time and high-energy source lithium-ion batteries are encountered. Lithium ion batteries are known as recharge- able secondary batteries. The long shelf life, wide operating range, high energy discharge capacity, lack of memory effect help the lithium-ion battery move higher among other batteries, but more preferable in the production of electric vehicles [4]. The most important disadvantage of these batteries is that they produce a lot of heat due to ohmic and entropic reactions during charge/discharge [5]. This increase in temperature during charging/discharging of HEVs and EVs can result in thermal leaks, explosions and injury to persons when they become irreparable and unstoppable [6].

The operating temperature range for Li-ion batteries is between $-20^{\circ} \mathrm{C}$ and $60{ }^{\circ} \mathrm{C}$ and the desired temperature range is between $15^{\circ} \mathrm{C}$ and $35^{\circ} \mathrm{C}$ to achieve high performance [7]. Temperatures outside the desired range cause significant capacity loss. For this reason, an effective Battery Temperature Management System is required to distribute the heat generated in the battery pack. In addition to the non-uniform temperature distribution between cells, the temperature imbalance within a cell is also an important source of problem. Since a large proportion of electrochemical reactions occur at the electrodes, the rate of heat generation is not the same in different locations within a Li-ion cell. A $\mathrm{LiCoO}_{2}$ positive electrode is reported to produce up to four times the heat of the entire battery [8]. Therefore, the temperature increase is not correct within the cell. This can result in the deterioration of the battery caused by local distortion, which 
has a negative impact on the performance of the entire cell. That's why, understanding the thermal behavior of the Liion battery and its thermal performance during discharge is becoming even more important.

Many studies have been performed based on the modelling of lithium ion batteries. Chen and Evans developed two and three-dimensional models and observed the thermal behaviour of the LIBS. They assumed that the heat generation rate was not altered throughout the cell [9-11]. Pals and Newman presented a one-dimensional model for a cell of lithium polymer batteries (LPBs) and predicted its thermal behavior [12]. Verbrugge modeled three-dimensional flow and temperature distributions in LPB modules [13]. Botte et al. used a mathematical model involving the carbon anode decomposition reaction to estimate the thermal behavior of LIBs under medium to high rate discharge conditions [14]. The simplified one-dimensional thermal modelling was presented by Al-Hallaj and others to observe the temperature distribution within the LIB cells [15]. The electrochemical-thermal model for LPBs by combining a two-dimensional thermal model and a one-dimensional electrochemical model was developed by Song and Evans [16]. Gu et al. developed a two-dimensional thermal and electrochemical model to analyze the thermal behavior of LIB cells [17-18]. A three-dimensional LIB model with convection and radiation-related boundaries was developed by Chen and his friends to examine different heat distribution performances on all surfaces [5]. Two-dimensional thermal modeling based on potential and current density distributions was presented by Kwon et al. [19-20].

In this study, the model of pouch type lithium ion battery was formed and its thermal behaviors at discharge rates of 0.5 C, 1 C, 2 C and 3 C were analyzed. It has been observed that the obtained model can be used in the design of a cooling system to eliminate non-uniform heat dissipation.

\section{MATHEMATICAL MODEL}

In a lithium-ion battery, the anode and cathode are made of active materials coated on the surface of the metal foils. A polymer separator is placed between the opposite polar foils to prevent the electrons from passing through them. Two models are used to estimate the development of chemical, thermal and electrical processes in a battery: 1) Single Potential Empirical Battery Model 2) Dual Potential MultiScale Multi-Domain (MSMD) Battery Model. The Single Potential Empirical Battery Model is useful if the geometry of the current collector, electrodes and separator is fully resolved. This model is best suited for electrode scale estimates in a single battery cell. However, the model is limited in battery systems, in particular to study all electrochemical events in complex geometry systems. Even for a single battery cell it would be very expensive to solve all layers clearly. In addition, many industrial applications use a battery pack consisting of a plurality of cells connected in series or parallel. MSMD battery model exceeds these limitations using a homogeneous model based on a multi-scale multi-dimensional approach. In this approach, the whole battery is considered as an orthotropic continuum; therefore, the network is no longer limited by the microstructure of the battery. To suit various analysis requirements, there are three electrochemical sub-models in the model; 1) Newman, Tiedemann, $\mathrm{Gu}$, and Kim (NTGK) empirical model, 2) Equivalent Circuit Model (ECM) and 3) Newman alts Pseudo 2D (P2D) model complexity level. The models offer the flexibility of examining physical and electrochemical phenomena emitted to various length scales in battery systems of various embodiments [21].

In this study, NTGK model was selected. This is because both it requires less parameters and is simpler to calculate [21]. This has been shown to be an advantage when supplying the battery, due to the difficulty of obtaining technical information. At the same time, the NTGK model is semi-experimental and requires battery discharge performance data to determine the polynomial coefficients of its parameters.

The internal structure of the pouch type battery consists of multiple positive and negative electrode layers, separators, positive and negative electrode current collectors and solid-state polymer electrolyte, which are made separately with the same shapes and structures. The outer layer of the battery cell is covered with aluminum plastic composite film. A porous separator is arranged between the positive and negative electrodes as shown in Figure 1 (a). Although the internal shape of the battery cell has a 3D structure, the discharge flow of the currents of each pair of electrodes appears as a $2 \mathrm{D}$ sandwich structure. It is time consuming to construct a mathematical model of the repeating electrical field, so the entire battery cell is simplified by generating only one pair of positive and negative electrodes, as shown in Figure 1 (b) [22]. In addition, the electric field parameters were obtained by the load protection equation. Finally, using a Computational Fluid Dynamics (CFD) method, the 3D mathematical model of the temperature field was obtained by combining the electric and temperature areas as shown in Figure 1 (c).

\subsection{NTGK Model}

The Newman, Tiedemann, Gu and Kim (NTGK) model is a simple empirical electrochemical model proposed by Kwon. In the model formulation, the volumetric flow transfer rate in Equation 1 relates to the potential field by the following algebraic equation:

$$
j_{E C h}=\alpha Y\left[U-\left(\varphi_{+}-\varphi_{-}\right)\right]
$$

Where, a: represents the specific area of the electrode plate, the phase potentials for the $\phi_{+}$and $\phi$. positive and negative electrodes $j_{E C h}$ represent the volumetric flow. $U$ and $Y$ are model parameters that show the functions of the discharge depth (DoD):

$$
j_{E C h}=\alpha Y\left[U-\left(\varphi_{+}-\varphi_{-}\right)\right]
$$




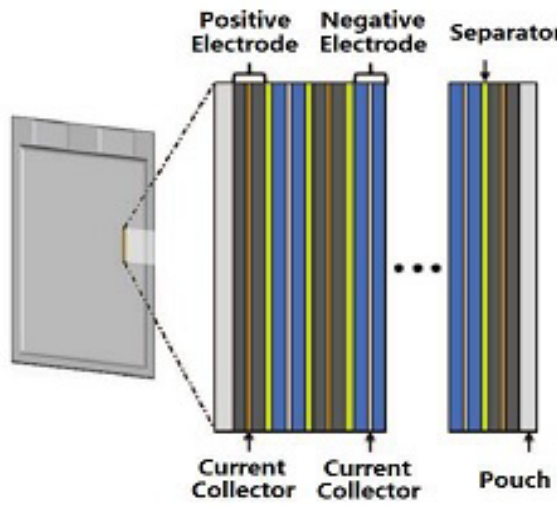

a)

agram of the modeling procedure of the pouct

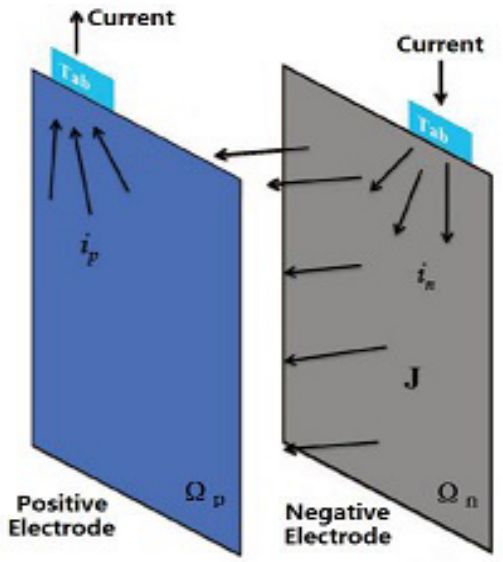

b)

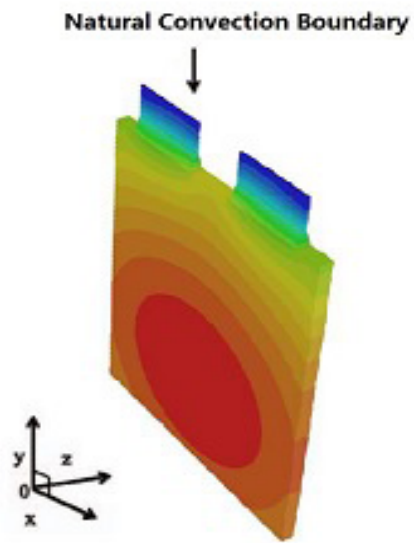

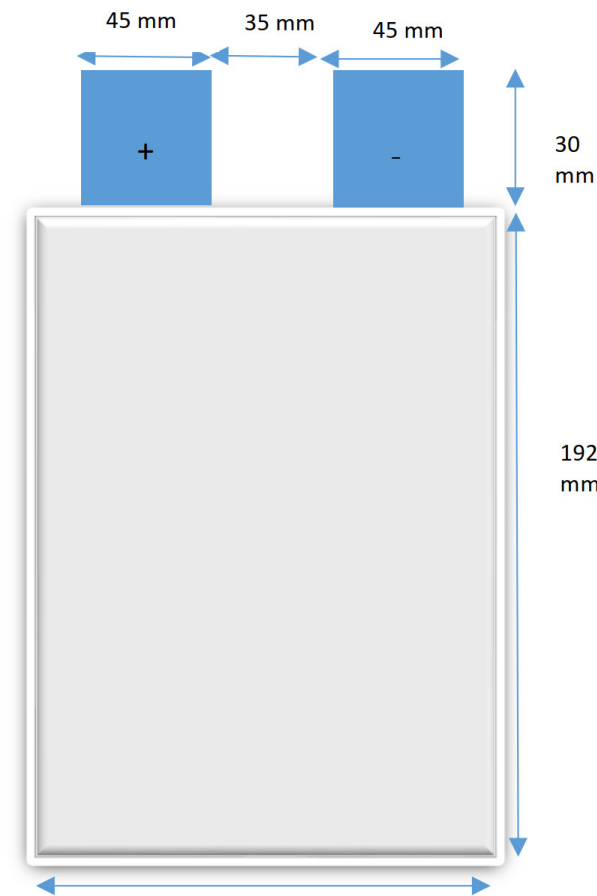

$145 \mathrm{~mm}$

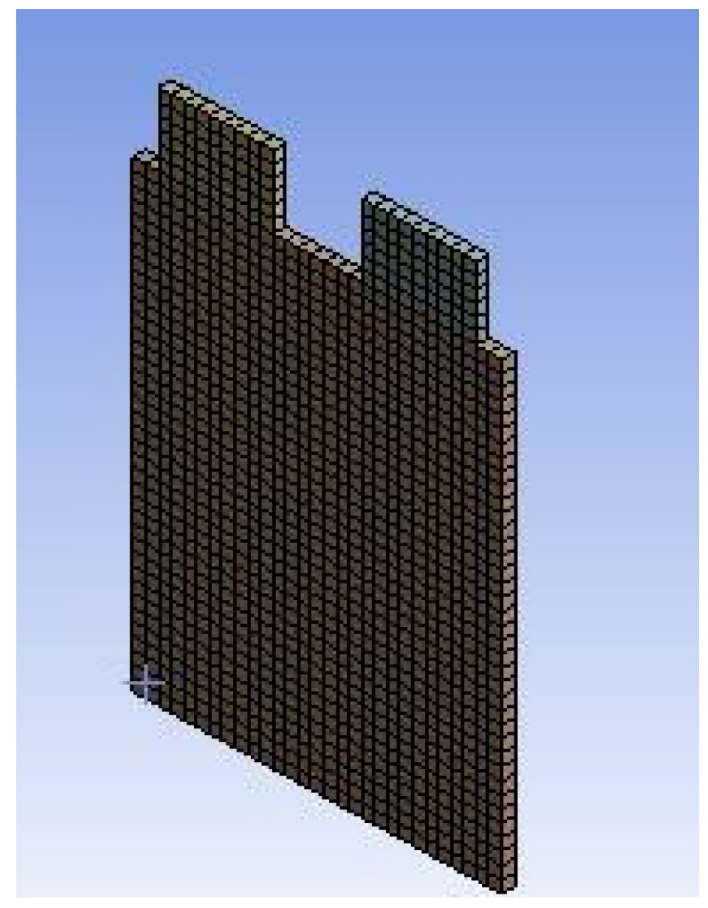

b)

Figure 2. a) 14.6 Ah LiMn $\mathrm{O}_{4}$ LIB dimensions b) Mesh image of the designed model

Vol, battery volume and $\mathrm{Q}_{\mathrm{Ah}}$ is total electrical capacity.

For a given battery, the voltage current response curve can be obtained by experimentation and then determined by the curve fitting the data. Kwon has adopted the following formulation for the proposed functions in [23]:

$$
\begin{aligned}
& Y=\left(\sum_{5}^{n=0} a_{n}(D o D)^{n}\right) \exp \left[-C_{1}\left(\frac{1}{T}-\frac{1}{T_{\text {ref }}}\right)\right] \\
& U=\left(\sum_{3}^{n=0} b_{n}(D o D)^{n}\right)-C_{2}\left(T-T_{\text {ref }}\right)
\end{aligned}
$$

Where, $C_{1}$ and $C_{2}$ are NTGK model's specific parameters.

The electrochemical reaction temperature is as follows;

$$
q_{E C h}=j_{E C h}\left[U-\left(\varphi_{+}-\varphi_{-}\right)-T \frac{d U}{d T}\right]
$$

The first term here is heat from over-voltage; the second term is heat from entropic heat.

\subsection{Model Parameters}

The dimensions of the 14.6 $\mathrm{Ah} \mathrm{LiMn}_{2} \mathrm{O}_{4} \mathrm{LIB}$ which are modeled in the package software program and the mesh size of this $3 \mathrm{D}$ geometry designed to be $0.005 \mathrm{~m}$ are shown in Figure 2 .

The default parameters used in NTGK model were taken in the studies in [24] and are shown in Table 1.

The study was used to obtain the discharge curves parameters of the typical 3.7 V lithium ion battery in [24]. Given that the NTGK model adjusts the capacity of the modeled battery cell, it is found that the default parameters for this research are sufficient.

\section{RESULTS AND DISCUSSION}

The simulations were obtained through the analysis pro- 
Table 1. MSMD Battery Module Input Parameters

\begin{tabular}{|c|c|c|}
\hline \multicolumn{3}{|c|}{ MSMD battery module parameters } \\
\hline Parameter & Value & Units \\
\hline \multicolumn{3}{|c|}{ Electrical parameters } \\
\hline Nominal Cell Capacity & 14.6 & $\mathrm{Ah}$ \\
\hline C-Rate & $0.5,1,2,3,5$ & - \\
\hline Min. Stopping voltage & 3 & V \\
\hline Max. Stopping voltage & 4 & V \\
\hline \multicolumn{3}{|c|}{ NTGK model polarization parameters } \\
\hline Initial DoD & 0 & - \\
\hline Capacity reference & 14.6 & $\mathrm{Ah}$ \\
\hline \multicolumn{3}{|c|}{ U constants: } \\
\hline $\mathrm{a} 0, \mathrm{a} 1, \mathrm{a} 2, \mathrm{a} 3, \mathrm{a} 4, \mathrm{a} 5$ & \multicolumn{2}{|c|}{$4.12,-0.804,1.075,-1.177,0,0$} \\
\hline \multicolumn{3}{|c|}{ Y constants: } \\
\hline b0,b1,b2,b3,b4,b5 & \multicolumn{2}{|c|}{$1168.59,-8928,52504.6,-136231,158531.7,-67578.5$} \\
\hline \multicolumn{3}{|c|}{ Temperature corrections: } \\
\hline $\mathrm{C} 1, \mathrm{C} 2$ & & \\
\hline \multicolumn{3}{|c|}{ Cell materials } \\
\hline Density & 2092 & $\mathrm{Kg} / \mathrm{m}^{3}$ \\
\hline Specific Heat (Cp) & 678 & $\mathrm{~J} / \mathrm{kg}-\mathrm{K}$ \\
\hline Thermal conductivity & 18.2 & $w / m-K$ \\
\hline UDS-0 & $1.19 e+06$ & $\mathrm{Kg} / \mathrm{m}-\mathrm{s}$ \\
\hline UDS-1 & $9.83 e+05$ & $\mathrm{Kg} / \mathrm{m}-\mathrm{s}$ \\
\hline Electrical conductivity & $3.541 e+07$ & Siemens/m \\
\hline \multicolumn{3}{|c|}{ Pole Materials } \\
\hline Density & 8978 & $\mathrm{Kg} / \mathrm{m}^{3}$ \\
\hline Specific Heat (Cp) & 381 & $\mathrm{~J} / \mathrm{kg}-\mathrm{K}$ \\
\hline Thermal conductivity & 387.6 & $w / m-K$ \\
\hline UDS-0 & Model parameters & $\mathrm{Kg} / \mathrm{m}-\mathrm{s}$ \\
\hline Electrical conductivity & $1 e+07$ & Siemens $/ \mathrm{m}$ \\
\hline
\end{tabular}

gram, which includes the finite element method using the mathematical methods and parameters shown in Chapter 2. Firstly, the MSMD battery has been selected according to the electrical parameters of the 14.6 Ah-LIB battery. Here, the minimum and maximum stopping voltages are shown as $3 \mathrm{~V}$ and $4 \mathrm{~V}$ respectively. This is because; the potential difference in charging or discharge of the battery does not damage the battery. It is under control that it does not fall below $3 \mathrm{~V}$ during discharge, and does not exceed $4 \mathrm{~V}$ during charging.

The discharge velocity parameters were applied as $0.5 \mathrm{C}, 1$ C, $2 \mathrm{C}$ and $3 \mathrm{C}$ respectively. The NTGK model polarization parameters are the default parameters for the model of the software package. Material information has been entered into the system as cell material and polar material. Although polar materials are chosen differently for positive and negative materials some studies, this study has been chosen the same for does not make a big difference. Since the boundary conditions are very small in the extremes of the poles, it is assumed that there is no heat loss. The boundary conditions for poles and cells were taken from the ambient temperature $300 \mathrm{~K}$ and the heat transfer coefficient (h) $5 \mathrm{w} / \mathrm{m}^{2} \mathrm{~K}$.

Figure 3 shows the temperature distributions in the discharge rates of $0.5 \mathrm{C}, 1 \mathrm{C}, 2 \mathrm{C}$ and $3 \mathrm{C}$ respectively. It is seen that the temperature rises gradually depending on the discharge rates. While the temperature is higher at the center of the cell, the temperature decreased to the poles. In 0.5
$\mathrm{C}$, the battery was discharged in 3000 seconds, although the average temperature was $300 \mathrm{~K}$, up to $302 \mathrm{~K}$ in $1 \mathrm{C}$. The battery has been discharged 1600 seconds in 2 C, 1200 seconds at $3 \mathrm{C}$ and the temperatures increased to $308 \mathrm{~K}$ and $314 \mathrm{~K}$.

Figure 4 shows discharge curves in the discharge rates of $0.5 \mathrm{C}, 1 \mathrm{C}, 2 \mathrm{C}$ and $3 \mathrm{C}$ respectively. As the discharge rate increases, the discharge time in the battery has been decreased. At the $0.5 \mathrm{C}$ discharge rate, the battery voltage decreased from $4.10 \mathrm{~V}$ to $3.86 \mathrm{~V}$ in 3000 seconds, at $1 \mathrm{C}$ discharge rate battery dropped from $4.10 \mathrm{~V}$ to $3.50 \mathrm{~V}$ in same time, at $2 \mathrm{C}$ discharge rate battery voltage decrease from $4.10 \mathrm{~V}$ to $3.30 \mathrm{~V}$ in 1600 seconds, at $3 \mathrm{C}$ discharge rate battery voltage decrease up to $3.20 \mathrm{~V}$ at 1200 seconds.

Figure 5 shows the total heat generation at discharge rates of $0.5 \mathrm{C}, 1 \mathrm{C}, 2 \mathrm{C}$ and $3 \mathrm{C}$ respectively. As shown in Figure 5, the total heat generation source was seen from the bottom of the cell to the upper layer of the cell. This is because the total flux density during charge and discharge is concentrated in the part of the cell towards the poles. As the rate of discharge rates increased, total heat production was observed to increase.

\section{CONCLUSIONS}

Because of the increasing popularity of electric vehicles, the batteries used in these vehicles have attracted the attention of the researchers. Despite the high cost compared to other 

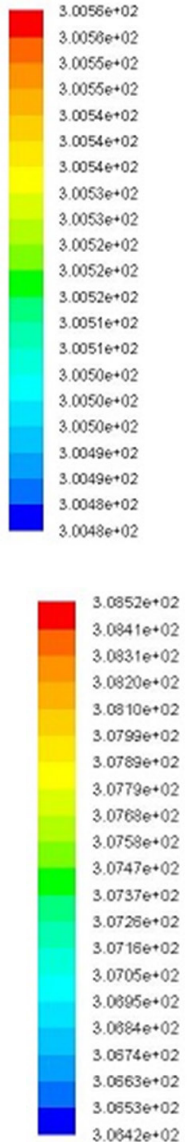

$.08520+02$ $3.08310+02$

$3.08200+02$

CB $10 \mathrm{e}+02$

$.07896+02$

$.03790+02$

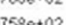

$.07370+02$

$07166+02$

$0705+02$

$3.0574 \mathrm{e}+02$

$3.05536+02$

$3.0642 e+02$

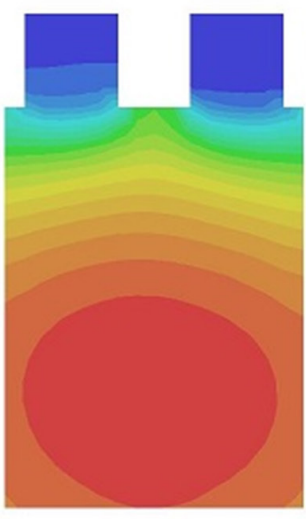

a)

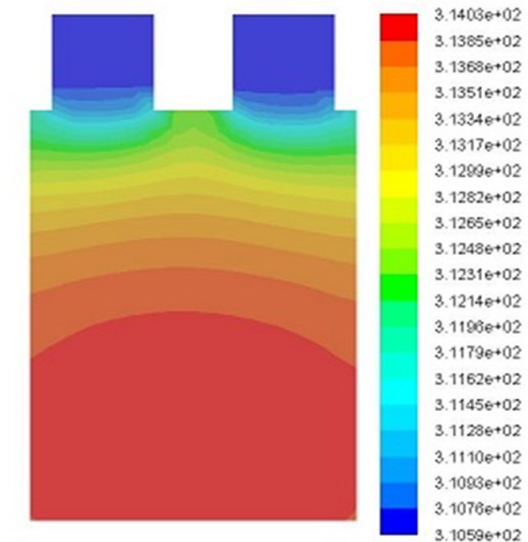

c)

Figure 3. Temperature distributions at a) $0.5 \mathrm{C}$ b) $1 \mathrm{C}$ c) $2 \mathrm{C} \mathrm{d}$ ) $3 \mathrm{C}$ discharge rates

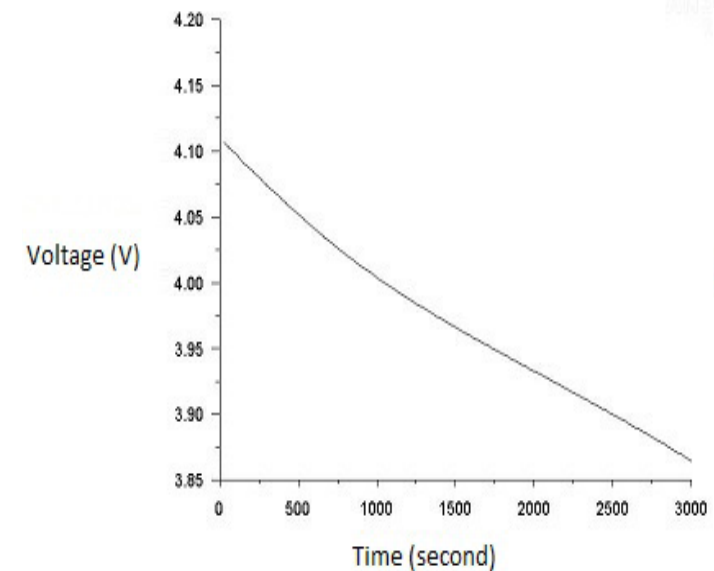

a)

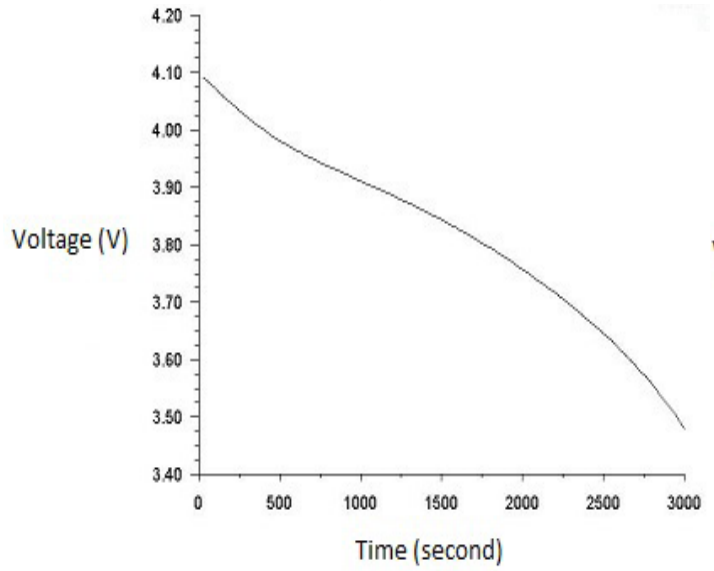

c)

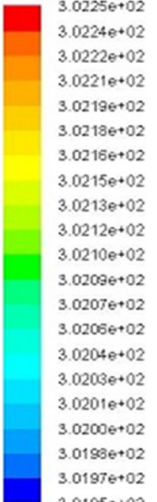

$301050+02$

d) b)
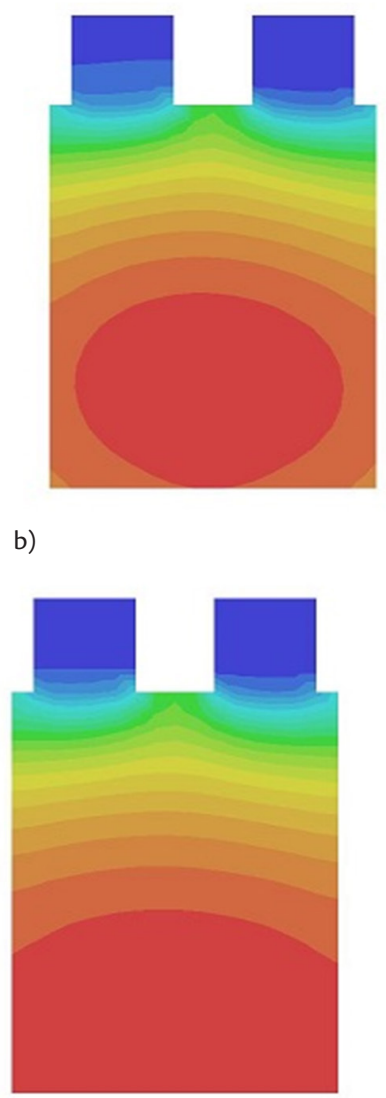

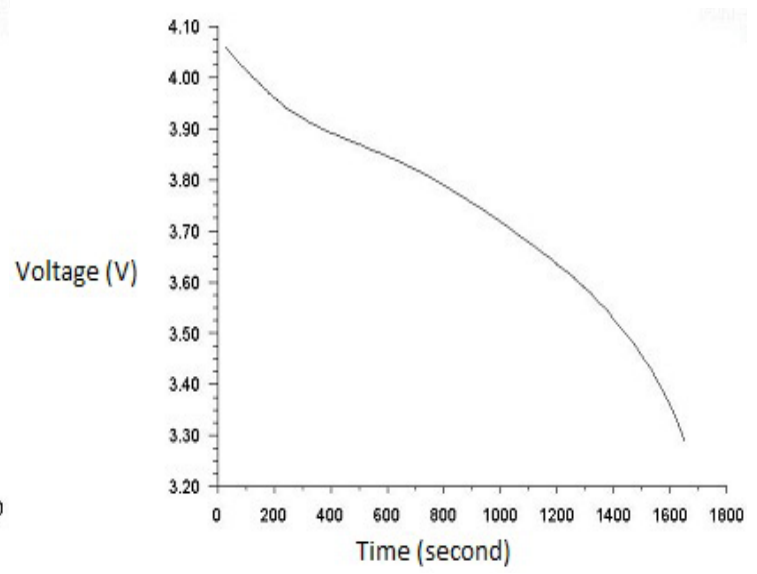

b)

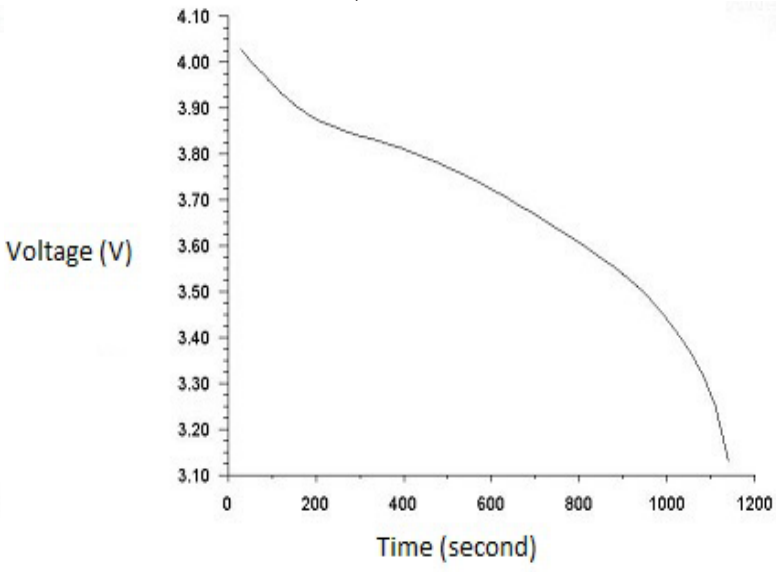

d)

Figure 4. Discharge curves at a) $0.5 \mathrm{C}$ b) $1 \mathrm{C}$ c) $2 \mathrm{C}$ d) $3 \mathrm{C}$ discharge rates 


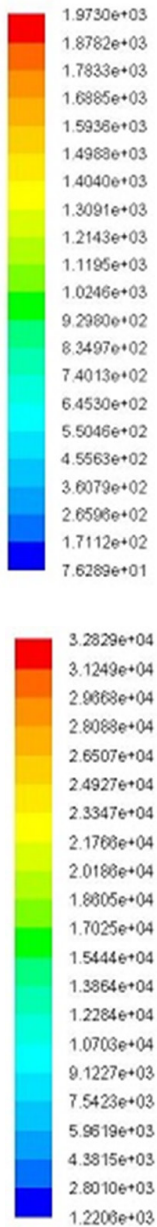

$.22066+03$

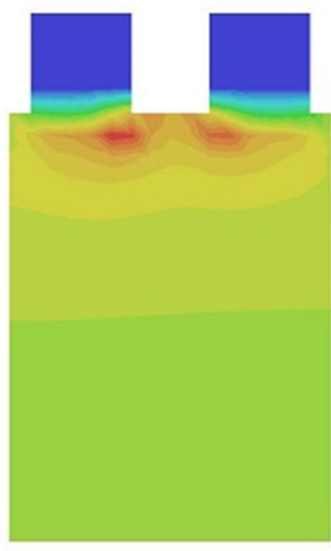

a)

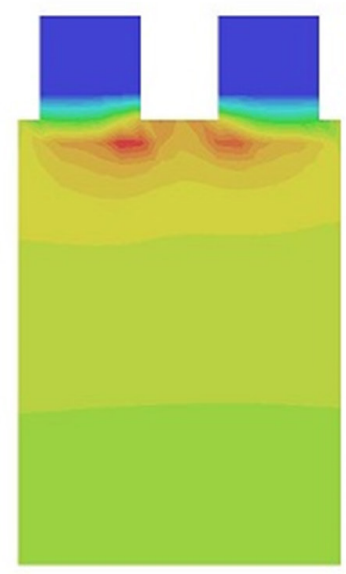

c)
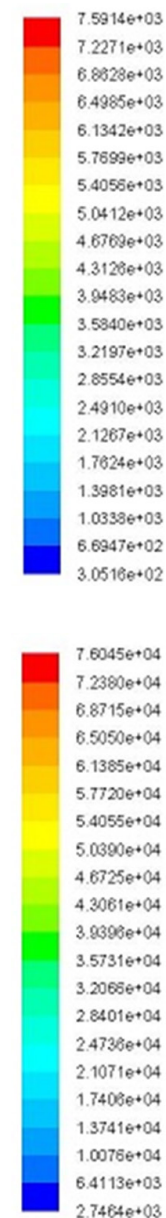

$2.74640+03$

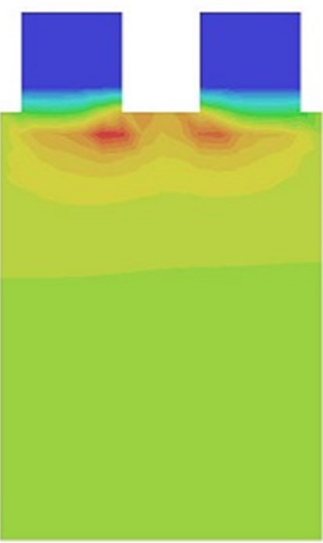

b)

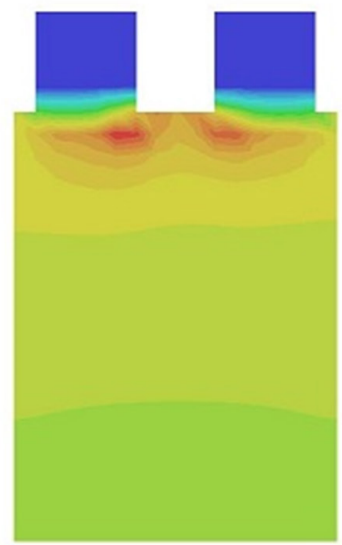

d)

Figure 5. Total heat generation at a) $0.5 \mathrm{C}$ b) $1 \mathrm{C} \mathrm{c}$ ) $2 \mathrm{C}$ d) $3 \mathrm{C}$ discharge rates

batteries, one of the reasons for reducing the life of lithium-ion batteries with high power and current density advantages is the high temperature and the explosion of heat leakage when it cannot be avoided. Therefore, temperature control has gained importance in both manufacturers and researchers.

In this study, real parameters obtained from discharge curves of a typical LIB of 14.6 Ah $3.7 \mathrm{~V}$ are used. At the same time, the pole and cell materials used were selected in accordance with the battery. The mesh size was chosen to be the closest to the true convergence by choosing a small size. Temperature profiles at discharge rates of $0.5 \mathrm{C} 1 \mathrm{C} 2 \mathrm{C}$ and $3 \mathrm{C}$ were examined. Examining the temperature distributions at different discharge rates and the total heat production is very important for the performance and health of the battery. It was observed that the total heat and temperature increased as the discharge time decreased at high discharge rates. This temperature was lower in the center of the cell and decreased towards the poles. Since the non-uniform distribution of the temperature also causes loss of capacity of the cell, a cooling system is needed to eliminate this uniformity. This study was a preliminary study for the design of the cooling system and was carried out to observe the thermal behavior of the battery in different discharge loads.

\section{REFERENCES}

[1] Keskin A. (2009). Hibrit Araç Teknolojileri ve Uygulamalar. Mühendislik ve Makine, 50(597): 12-20.

[2] Yufei, C., James, E. (1993). Heat Transfer Phenomena in Lithium/Polymer- Electrolyte Batteries for Electric Vehicle Application. Journal of Electrochemical Society, 140(7): 1833-1838. doi: 10.1149/1.2220724.

[3] Şenlik, I. (2015).Uyuyan Devrim: Elektrikli Araçlar. Elektrik Mühendisliği Dergisi, 455: 64-67.

[4] Linden, D., Reddy, T. (2002). Handbook of Batteries, Third Eddition. McGraw-Hill, Section 22 and 35.

[5] Chen, S., Wan C. C., Wang Y. Y. (2005). Thermal Analysis of LithiumIon Batteries. Journal of Power Sources, 140: 111-124.

[6] Wang, B. G., Chin, Y. W. (2000). Thermal-Electrochemical Modeling of Battery Systems. Journal of Electrochemical Society, 147(8): 29102922. doi: 10.1149/1.1393625.

[7] Tie, S. F., Tan, C. W. (2013). A Review of Energy Sources and Energy Management System in Electric Vehicles. Renewable and Sustainable Energy Reviews, 20: 82- 102. doi: 10.1016/.jrser.2012.11.077.

[8] Huang, Q., Yan, M., Jiang, Z. (2006). Thermal study on single electrodes in lithium-ion battery. Journal of the Power Sources, 156: 541-546. doi: 10.1016/j.jpowsour.2005.05.083.

[9] Yufai, C., James, W. E. (1993). Heat Transfer Phenomena in Lithium/Polymer-Electrolyte Batteries for Electric Vehicle Application. Journal of the Electrochemical Society, 140: 1833-1838. doi: $10.1149 / 1.2220724$. 
[10] Yufai, C., James, W. E. (1994). Three-Dimensional Thermal Modeling of Lithium-Polymer Batteries under Galvanostatic Discharge and Dynamic Power Profile. Journal of the Electrochemical Society, 141: 2947-2955. doi: 10.1149/1.2059263.

[11] Yufai C., James, W. E. (1996). Thermal Analysis of Lithium-lon Batteries. Journal of the Electrochemical Society, 143: 2708-2712.

[12] Pals, C. R., Newman, J. (1995). Thermal Modeling of the Lithium/ Polymer Battery. Journal of the Electrochemical Society, 142: 32743281.

[13] Newman, J., Thomas, K. E. (2012). Electrochemical Systems. John Wiley \& Sons.

[14] Botte, G. G., Johnson, B. A., White, R. E. (1999). Influence of Some Design Variables on the Thermal Behavior of a Lithium-lon Cell. Journal of the Electrochemical Society, 146: 914-923. doi: $10.1149 / 1.1391700$.

[15] Al-Hallaj, S., Maleki, H., Hong, J. S., Selman, J. R. (1999). Thermal modeling and design considerations of lithium-ion batteries. Journal of the Power Sources, 83: 1-8. doi: 10.1016/S0378-7753(99)00178-0.

[16] Song, L., Evans, J. W. (2000). Electrochemical-Thermal Model of Lithium Polymer Batteries. Journal of the Electrochemical Society, 147: 2086-2095. doi: 10.1149/1.1393490.

[17] Gu, W. B., Wang, C. Y. (2000). Thermal-Electrochemical Modeling of Battery Systems. Journal of the Electrochemical Society, 147: 29102922. DOI: 10.1149/1.1393625.

[18] Gu, W. B., Wang C. Y. (2000). Thermal-Electrochemical Coupled Modeling of a Lithium-Ion Cell. Journal of the Electrochemical Society, 145: 3418-3429.

[19] Kim, U. S., Shin, C. B., Kim, S. (2008). Thermal modeling and cooling analysis of high-power lithium ion cells. Journal of the Power Sources, 180: 570-575. doi: 10.1007/s11630-011-0512-3.

[20] Kim, U. S., Shin, C. B., Kim, S. (2009). Modeling for the scale-up of a lithium-ion polymer battery. Journal of the Power Sources, 189: 841-846. doi: j.jpowsour.2008.10.019.

[21] ANSYS Fluent Advanced Add-On Modules Manual (2015). ANSYS ${ }^{\oplus}$, Inc. Canonsburg, PA: SAS IP Inc.

[22] Yi, J., Kim, U. S., Shin, C. B., Han, T., Park, S. (2013). Three-dimensional thermal modeling of a lithium-ion battery considering the combined effects of the electrical and thermal contact resistances between current collecting tab and lead wire. Journal of the Electrochemical Society, 160: A434-A443. doi: 10.1149/2.039303jes.

[23] Kwon, K. H. (2006). A Two-dimensional Modeling of a Lithium polymer battery. Journal of Power Sources, 163:151-157. doi: 10.1016/j. jpowsour.2006.03.012

[24] Kim, U., Yi, J., Chin, S., Han, T., Park, S. (2011). Modeling the Dependence of the Discharge Behavior of a Lithium-lon Battery on the Environmental Temperature. The Journal of the Electrochemical Society, 158: 611-618. doi: 10.1149/1.3565179 